\title{
Research on Innovation Driving Force and Industrial Upgrading under Information Technology
}

\author{
Guotie Chen, Associate Professor, \\ Management College, Fujian University of Technology \\ Fuzhou, China, \\ gtchen@fjut.edu.cn
}

\begin{abstract}
With the deepening of the information technology revolution, the concept of innovation became more and more popular. The innovation has become the core of all activities of enterprises or industries. We need to systematically consider the connotation and driving force of innovation. This paper discussed the innovation model, new changes and the impact on industrial upgrading under the information technology, and put forward the corresponding paths and countermeasures.
\end{abstract}

Keyword- Information Technology; Innovation Driven; Dynamic Mechanism; Industrial Upgrading

\section{Introduction}

Innovation is a new mode of behavior. In the role of against old thinking, through research, analysis, digestion and transformation, the innovation industry produces more or better quality, or better performance products, create more social wealth with new manufacturing technology, organization mode, the amounts of resources. The innovation contains great content and fields. In production, the innovation includes engineering design, engineering research, product development, production technology, engineering construction, equipment maintenance, product marketing and so on. In the ideological field, the innovation includes management, ideas, artistic creation and so on. Since the innovation is involved in every field of social and economic development, and it is not isolated, but generally connected. It exists both internal forces and external forces, and it is also affected by positive and negative factors.

Peter. Drucker points out that the innovation is the new act of giving resources to create more wealth. Schmookler (1966) sets up the demand pull model of enterprise innovation, and proposes that the innovation activities of American enterprises are pursuing maximum profits under the guidance and restriction of market demand. Domestic scholar Hong Yinxing (2011) believes that innovation driven uses basic elements, such as technology, knowledge, enterprise management system and operation mode, etc. to integrate or re-integrate enterprise production resources. Zhang Yinyin (2015) believed that the innovation updates the system engineering, organization structure, business model. It is an important contribution to the upgrading of the industrial structure. He put forward three path of the innovation driven for industry upgrading: technical trajectory, market track, whole industry chain. Ye Feiwen (2015) pointed out that industrial upgrading should be driven by innovation, and constantly upgrade products through technological innovation, so as to survive in the domestic and foreign market competition. In summary, scholars at home and abroad have more research on innovation driven and industrial upgrading. But there is still little research on innovation under the information technology or the new generation of Internet technology. Therefore, the research of this paper is necessary.

\section{The composition of the driving force of innovation}

According to the theory of technological innovation, the driving force of innovation is the key to technological innovation. The driving force of innovation is divided into internal and external driving forces. Internal driving force includes entrepreneurship, business objectives and the nature of enterprise innovation. External driving force includes market competition, demand pull, technology development and government intervention.

\section{A. Internal driving force}

1. Entrepreneurship

Entrepreneurs are inherently adventurous and innovative. Their difference from ordinary people lies in entrepreneurial awareness and creativity. They don't seek stability, but seek opportunities at risk. Therefore, the "old leather update" and "active entrepreneurship" have become the intrinsic characteristics of entrepreneurship. In the innovation activity, the entrepreneur groups constitute the main body of decision-making, the investment, the research and development in the innovation system. Entrepreneurs strengthen spillovers of knowledge and complementarities of experience through job exchange and flow. Entrepreneurs promote the continuous optimization and upgrading of the industry through innovation, and avoid development in the stagnation. Since the reform and opening up, innovative spirit and ability of the Pearl River Delta 's entrepreneur had been fully brought into play, and making small and medium-sized enterprises blossom everywhere and develop in an all-round way in the Pearl River Delta. Eighty-fifth per cent of medium-sized and small enterprises have created Economic miracle of the Pearl River.

\section{Business objectives}

The objective of enterprise management is to maximize the benefits, including the maximization of economic benefits or social effect. If a company wants to win in the fierce competition in the market, the key is that its products and business philosophy can be accepted by consumers. This forces enterprises to invent and produce more new products with higher quality, lower price and more green. Thus, enterprises are urged to carry out management innovation, technological innovation and conceptual innovation. The innovative behavior and innovation spirit of individual enterprises have gradually become the main trend of 


\section{Enterprise innovation culture}

The Confucian classics "Daxue" mentioned that "Gou Ri Xin, Ri Ri Xin" from "Pangming" of Tang Dynasties means updating every day. The term "innovation" originated here, and it emphasizes the need for continuous innovation from a dynamic perspective. It is actually attaches great importance to innovation in China's traditional culture, rather than carving on gunwale of a moving boat. It also requires that enterprises have a new attitude to update the technology. Since the reform and opening, China's enterprises have carried out innovative activities, actively developed research and development with risks. From early imitation to overtaking, our enterprises continue to develop new technologies, develop new products, give birth to new industries, seize the commanding heights of technological and promote the rapid take-off of China's economy.

\section{B. External driving force}

\section{Market driven by competition}

The wave of industrial revolution sweeping the globe, the information technology has caused a great and deep influence to the production and life style of human society. Under the domestic market and international market competition, enterprises maintain its competitiveness only through caring out constant innovation and meet the times, otherwise it also Prosperous and death suddenly. NOKIA, a former maker of mobile phones in the world, has been unable to meet consumer demand because of its lack of innovation, and it has evaporated in a few years. Therefore, market driven by competition is the biggest external impetus for enterprises or industries to carry out innovation.

\section{Market driven demand}

According to the theory of technological innovation, the scale and direction of innovation are affected by the scale and structure of social demand. From the actual situation of social and economic development, the scale and structure of the market demand directly affect the industrial structure and economic growth of a country. The scale and structure of demand are always changing with the advance of human society. The human needs better goods and newer services, which will drive the continuous innovation of manufacturing technology and business model, and promote the innovation and development of industries and enterprises. For example, innovation activities of China's high-speed rail technology rapidly grow the developed production technology of high-speed rail in the word from absorption digestion to re innovation. This is inseparable from China's huge market demand. There will be no brilliant innovation of China's high-speed rail technology today without China's market scale and demand.

\section{Technology development}

With the continuous deepening of the scientific and technological revolution, the invention and discovery of technology is very faster than before, which drives enterprises to carry out technological innovation in an all-round way. There was the phenomenon of "Discovery in England, Invention in America" in the western. American enterprises had vigorously introduced the technology of European advanced industrial countries, then studied, transformed, innovated, and quickly surpassed the European countries in the industrialization stage of development. With the overall development of big data technology, the western developed countries layout the high-tech in advance in the post industrialization era. The Obama administration launched "Big Data Research and Development Initiative" in 2015 and took the big data as a strategic technological development. USA comprehensively promoted the whole society to carry out innovative activities of each body from the national level, industrial and enterprise level.

\section{Government intervention}

Whether innovative activities can be fully implemented and developed, it is closely related to government intervention. In the key technologies, fundamental research and other market failure fields, the innovation involves great risks and economic burdens, such as the project of human genome, the strategy technology of national network, the technology of national aerospace, and so on. As these areas are related to strategies of national security, the government needs strong intervention to formulate strong innovation policies of industrial and systems of innovative investment. At the same time, the government should do well to guide public funds and private investment, and do a good job of services of enterprise innovation, protection of intellectual property and maintenance of innovative market order. The government can accelerate the development and commercialization of new technologies, supports innovation and entrepreneurship in the manufacturing sector, enhances the vitality and potential of the supply chain of emerging industries, and achieves industrial transformation and upgrading. In addition, the government should guarantee the growth space of company and order of market competition, and improve the legal and regulatory systems for unfair competition and anti-monopoly.

\section{New mode of innovation}

With the continuous evolution of information technology and the new industrial revolution, the economic structure of the traditional market is changing to the environment based on the supply chain ecosystem. This change starts from the way of innovation driven of the following three aspects.

\section{A. Consumers involving in innovation process}

The technology of internet of things has become the fusion agent and catalyst for enterprises and consumers in the value supply chain. Consumers and enterprises directly contact each other. Co creation, joint financing, joint design, joint production, joint marketing and joint distribution have become common view. On the basis of trust, consumers and enterprises work together to jointly create value in a relatively standardized and transparent market environment.

\section{B. The supply chain ecosystem redefining the implications of innovation}

The ecosystem of supply chain is a complex system formed in the development of industrial economy. Complex systems of value chain are made up of many independent businesses and customer relationships. This new supply chain drives changes of innovation patterns, such as collaboration between Quirky and GE. GE used Quirky system to crowd sourcing and to expand GE innovation capability. They effectively reduce innovation risk and financial risk. They also found a great deal of creative talent, realized the value of wealth and achieved a win-win situation. 
C. Information technology has become the core of innovation.

With the technology of the broadband, enterprises can quickly learn the changes in customer demands and timely respond by the high mutual exchange of information. The burgeoning internet finance of China develops also based on the analysis of consumer transactions of a large number of online communities and users.

IV. The impact of innovation driven on industrial transformation and upgrading

Through the above analysis, the internal and external driving forces and new patterns of innovation are changing, and industrial upgrading is also changes in the continuous evolution of information technology. Under the support of information technology, the elements and resources of value supply chain are re decomposed, integrated and absorbed by innovation. It will promote the benign interaction of the advanced manufacturing, advanced services, high-tech industries, and the advantages of traditional manufacturing industry. Cultivate new industries, new formats and new models. New industries, new formats and new models will be cultivated, and the innovation circle of the supply chain will be constructed. These measures will effectively promote industrial restructuring and upgrading.

\section{A. Priority to the development of modern service industries}

We can innovatively apply the technology of internet and the technology of internet of things. We should vigorously develop the service industry relying on knowledge factor, the intelligence platform of universities and scientific institutions, and comprehensively applying finance and taxation policies. The service industries, such as the design industry, information industry, technical services industry, finance and insurance industry, and service outsourcing industry, should be vigorously developed. The commercial operation mode of modern service industry need be changed. These methods will drive the overall upgrading of the service industry. Finally, we will promote the overall upgrading of the service industry by innovating the business model of the modern service industry.

\section{B. Accelerating the development of advanced} manufacturing

We should develop strategic emerging industries or other new industries, and create the core competitiveness of industries, especially in accordance with local advantages, local conditions by using of modern information technology. We will energetically develop the modern advanced manufacturing industry with great market potential and rapid technological progress. We will focus on the development of modern manufacturing such as modern equipment, shipbuilding, automobile manufacturing, new materials, new energy sources, and new medicine with strong driving force, high degree of correlation and intensive technology.

\section{Transformation, enhance the advantages of} traditional industries

We should draw on the successful experience of other countries and regions to promote the integration of traditional industries and high-tech. It will transfer the lack of comparative advantages and low value-added industries or production sectors into low industrial gradient areas through carrying out organizational innovation and business model innovation. At the same time the advantages of traditional enterprises can integrate resources of value supply chain by supporting of government, and set up innovation platforms of $\mathrm{R} \& \mathrm{D}$ and sharing platforms of market. Traditional industries utilize R\&D and market to achieve high-end development by centralizing and attracting, and realize transition and upgrade.

V. The construction path and Countermeasures of industry transformation and upgrading

A. Establishing the mechanism of innovative fund

We should increase investment in SMEs innovation because the current cost of innovation is generally high. In the process of innovation, the government will increase the investment of funds and form a relatively loose financing channel for innovation. On the one hand, we should increase investment in innovative small and medium-sized enterprises, and change the focus of R\&D funds into large enterprises or state-owned enterprises, so as to enhance the initiative of small and medium-sized firms in scientific and technological innovation. On the other hand, a reasonable system of risk investment should be established to encourage the venture capital funds and its mechanism. It will provide convenient conditions for new technology and products to obtain venture capital, and provide provide high quality channels and guarantee for the smooth marketing of innovative achievements.

\section{B. Establishing a good innovation culture and environment}

The government and society should actively explore and carry forward the innovative spirit of our traditional culture. In particular, we should refine the traditional innovation and entrepreneurship of regional businessmen such as the Pearl River Delta, Yangtze River Delta and southern region of Fujian, so as to create a sense of innovation for all and create a positive and innovative culture. At the same time, we should strengthen and improve infrastructure construction, intellectual property rights construction and innovation legal system construction, and provide a good environment for innovative talents to carry out innovative activities. Moreover we should strengthen cooperation between local governments, industries, enterprises and universities. The government should play its due role in innovation, and organize industries to set up innovation research institutes and initial innovation fund. We should encourage social capitals to be widely invested in innovation and industrialization. In addition, we must continue to improve the PPP Project Finance Cooperation Model, and make full use of the leverage of the policy, such as taxation, investment and financing to foster a good environment.

\section{Training innovative talents through improving the} cooperation mechanism between industries and universities.

Researchers in universities and institutions are the core forces in the system of innovation and the main part of innovative talents. Globally, the areas of innovation agglomeration are the places where universities and institutions are gathered. They form a mechanisms of cooperation similar to the ecosystem of between. The innovation of enterprises need the talents of universities and institutions, and also provide practice bases for training innovative talents in universities and colleges. The relationship between them is mutually reinforcing. Silicon Valley, for example, has made great technological advances and commercial success in collaboration with the high degree cooperation of industry, University and research. The Stanford University and the University of California at Berkeley are the fountain of wonders and the source of success for Silicon 
Valley. At the same time, Silicon Valley also provides an excellent environment for the training of innovative talents in universities.

\section{Technology driven and application driven simultaneously.}

In the context of the new industrial revolution, the relationship between government, enterprises and consumers is becoming closer and closer. The flat organizational structure of enterprises and the cooperative model decentralized business is becoming more and more popular. The cooperation between government and enterprises, between enterprises and enterprises, between enterprises and consumers is of great importance when they are facing the increasingly complex and systematic requirements. They need establish a new model of cooperation, build innovative platforms, play their comparative advantages, and form a professional division of labor relations. We should promote the extensive integration and deep application of information networks, new materials, new energy or renewable energy technologies, and then foster new industries, new formats and new models. Therefore, it will promote the transformation of industrial structure.

\section{Conclusions}

At present, China is in a new normal social and economic situation, and it is also a critical period to change the mode of economic growth. The global industrial structure and industrial transfer are undergoing great changes. Therefore, it is necessary to systematically analyze the power of innovation and upgrade of industrial transformation under information technology. It is positive significance for promoting the upgrading of China's industrial structure from understanding its connotation and operating mechanism.

\section{References}

[1] OECO. The knowledge based economic: The National Innovation System [R].1996-1997.

[2] Agrawal, Ajay, Iain Cockburn, Alberto Galasso, and Alexander Oettl, - Why are Some Regions More Innovative than Others? The Role of Firm Size Diversity, NBER Working Paper 17793 (2012).

[3] Ellison, Glenn, and Edward Glaeser, -Geographic Concentration in U.S. Manufacturing Industries: A Dartboard Approach, Journal of Political Economy 105 (1997), 889-927.

[4] Kerr, William, and Ramana Nanda, -Financing Constraints and Entrepreneurshipl, in Audretsch, David, Oliver Falck, and Stephan Heblich (eds.) Handbook of Research on Innovation and Entrepreneurship (Cheltenham, U.K.: Edward Elgar Publishing, 2011), 88-103.

[5] Klapper, Leora, Raphael Amit, and Mauro F. Guillén, Entrepreneurship and Firm Formation across Countries, in Lerner, Josh, and Antoinette Schoar (eds.) International Differences in Entrepreneurship (Chicago, IL: University of Chicago Press, 2010).

[6] Chris Freeman, (Hongxun Hua). Chinese translation. Industrial innovation economics [M]. Peking University press, 2005:193

[7] Hong Yinxing. On innovation driven and innovation economy several important concepts of [J]. Masses, 2011 (08).25-29.

[8] Zhang Yinyin, Huang Bin. Research on the path of innovation driven industrial structure upgrading $[\mathrm{J}]$. Exploration of Economic Issues, 2015 (3): 107-112.

[9] Leaves Feiwen. Promote industrial upgrading and transformation to build on the development version of $[\mathrm{J}]$. Upgrade of Fujian industry, 2015 (9): 38-40. 